\title{
O discurso sobre um 'ditador': uma análise crítico-discursiva
}

\author{
Cibelia Renata da Silva Pires* \\ USP \\ Recebido em: 30/04/2019 \\ Aceito em: 15/12/2019
}

Resumo: Baseado nos pressupostos teórico-metodológicos da Análise Crítica do Discurso (Fairclough 2001, 2003) e na Linguística Sistêmico-Funcional de Halliday e Matthiessen (2004), este artigo tem por objetivo demonstrar quais estratégias linguísticas foram utilizadas pela revista Veja na construção da imagem social do ex-presidente venezuelano Hugo Chávez. Para isto, utilizamos como corpus a reportagem "Louco por uma guerrinha". O resultado desta análise nos mostra que a revista sustenta um discurso contrário a Chávez, construindo a imagem de um presidente autoritário, personalista e um perigo que ultrapassa as fronteiras de seu país.

Palavras-chave: Hugo Chávez. Venezuela. Análise Crítica do Discurso. Linguística SistêmicoFuncional.

\begin{abstract}
Based on the theoretical-methodological assumptions of critical discourse analysis (Fairclough 2001,2003) and Halliday e Matthiessen's Systemic-functional linguistics, this article aims to demonstrate which linguistics strategies were used by Veja magazine in the construction of the social image of the former Venezuelan president Hugo Chávez. For this, we use as a corpus reporting "Crazy about a war". The result of this analysis shows that the magazine sustains a discourse against Chávez, constructing an image of an authoritarian, personalist president and a danger that goes beyond the borders of his country.
\end{abstract}

Keywords: Hugo Chávez. Venezuela. Critical analysis of discourse. Systemic-functional linguistics.

Resumen: Que se basa en los supuestos teorico-metodológicos Del análisis crítico Del discurso (Fairclough 2001,2003) y em la Linguística Sistemática-Funcional de Halliday e Matthiessen (2004), este artículo tiene por objetivo demonstrar qué estrategias linguísticas fueron utilizadas por la revista Veja em la construcción de la imagem social de Chávez. Para ello, utilizamos como corpus El reportaje "loco por uma guerrinha". El resultado de este análisis nos muestra que la revista sostiene un discurso contrario a Chávez, construyendo una imagen de um presidente autoritário, personalista y um peligro que sobrepasa las fronteras de su país.

Palabras clave: Hugo Chávez. Venezuela. Analisis crítica del discurso. Linguística SistemáticaFuncional.

\section{Introdução}


Desde que venceu as eleições em 1998, na Venezuela, até a sua morte, o presidente Hugo Chávez Frias ocupou com frequência as páginas de jornais e revistas não só na Venezuela como também no Brasil. Considerado hoje o país com a maior reserva de petróleo do mundo, a Venezuela, país localizado na América do Sul, tem sido alvo de interesses estrangeiros que buscam novas fontes de exploração desse recurso cada vez mais escasso (SEVERO, 2012, p.115).

A ascensão de Hugo Chávez à presidência fez com que a Venezuela entrasse em um processo de profundas transformações sociais, econômicas e políticas. Com base no que ele chamou de socialismo do século XXI, o governo bolivariano ganhou projeção internacional devido às diversas mudanças que operou na política interna, bem como por ter mantido uma nova postura na política externa, que se caracterizou pelo não alinhamento com os EUA.

Chavez aderiu aos projetos de integração regional (UNASUL, ALBA e MERCOSUL) como alternativa ao alinhamento estadunidense, implementou reformas de caráter nacional-desenvolvimentista, afastou-se do modelo econômico liberal e, com as rendas provenientes do aumento do preço do petróleo, investiu em projetos sociais, além de criar uma área de influência própria na América Latina (MENDES, 2012).

O afastamento do modelo econômico liberal, a contínua contestação em relação à liderança global norte-americana e o discurso de caráter nacionalista abriram caminho para a intensa rivalidade entre a Venezuela e os EUA. Esse antagonismo se manteve presente durante todo o mandato de Hugo Chavez e continuou mesmo após sua morte em 2013.

Esta pesquisa tem como base os pressupostos teóricos da Análise Crítica do Discurso (ACD), especificamente o enfoque feito pelo linguista Norman Fairclough (2003, 2001). A ACD propõe um arcabouço teórico-metodológico para a explicação crítica de questões ligadas à relação de poder e dominação no plano sociodiscursivo. Como instrumental teórico para a análise das práticas discursivas, a ACD busca deslindar a relação dialética entre linguagem e sociedade, observando como o discurso pode sofrer intervenções dos elementos históricos, ideológicos e culturais. Ao analisar o discurso como prática social que reflete as relações de poder, a ACD não só denuncia os diversos conflitos sociais e, por consequência, as práticas de dominação neles envolvidos, como 
também explora e propõe projetos de mudança social, a fim de ampliar a participação democrática e contribuir para uma emancipação social.

A relação assimétrica entre os meios de comunicação e a sociedade pode ser entendida como um problema social, tendo em vista que essa relação sustenta uma associação assimétrica de poder entre aqueles que detêm o espaço para veicular suas ideias e, portanto, o poder de fala, e aqueles que apenas têm acesso a essas publicações e discursos. Segundo Giannotti (2004, p. 167), “(...) para Veja e toda mídia que defende a mesma classe que ela, a função da mídia é impedir qualquer mudança nos rumos da sociedade. Seu objetivo é manter, conservar, proteger, defender sua classe".

Um dos objetivos da ACD é verificar a função do discurso no interior de problemas sociais contextualmente situados, ocupando-se com os efeitos ideológicos produzidos por meio de textos (discursos) nas relações sociais. Para Fairclough (2003, p. 8), textos podem conduzir a mudanças em nosso conhecimento, nossas crenças, atitudes e valores. Tendo em vista que a relação entre mídia e sociedade ocorre por meio de textos (discursos), podemos enfatizar a natureza social dessa relação e promover, por meio dessas mesmas práticas discursivas, as mudanças sociais necessárias.

Desse modo, este referencial teórico tem-se mostrado bastante eficaz para quem quiser fazer um estudo sobre língua e a influência do contexto histórico e social na produção do discurso, bem como nas diversas formas de reprodução de discriminação, legitimação do poder, manipulação do consentimento que se refletem na produção discursiva dos diversos atores sociais, principalmente dos meios de comunicação. Segundo Melo (2010):
A ACD entende o discurso tanto como reprodutor quanto transformador de realidades sociais e o sujeito da linguagem, a partir de uma perspectiva psicossocial, como não só propenso ao moldamento ideológico e linguístico, mas também agindo como transformador de suas próprias práticas discursivas, contestando e reestruturando a dominação e as formações ideológicas socialmente empreendidas em seus discursos. Para a ACD, o sujeito e o discurso se constituem num processo dialético, que ora se conforma às práticas discursivas/sociais que o compõem, ora resiste a elas, ressignificando as, reconfigurando- as (MELO, 2010, p. 85).

Para a análise de dados, utilizaremos também a Linguística Sistêmico-Funcional (LSF) de Halliday e Matthiessen (2004), mais especificamente as categorias que compõem o sistema de transitividade verbal referente à metafunção ideacional, a fim de compreender os diferentes tipos de processos e o modo como se articulam para construir 
a imagem social do ex-presidente Hugo Chávez. Para Fairclough (2003, p. 5), ao contrário de outras teorias linguísticas, “a LSF está profundamente interessada na relação entre linguagem e outros elementos e aspectos da vida social, e sua abordagem para a análise linguística de textos está sempre orientada para o caráter social dos textos”. Isso faz dela um recurso valioso para a ACD. Por esse motivo que Chouliaraki e Fairclough (1999) entendem que a LSF é a teoria linguística que mais tem em comum com a ACD e mais tem a oferecer a ela. Ambas as teorias compreendem a linguagem como um construto social e partilham de uma visão dialética da linguagem, em que os eventos discursivos particulares influenciam seus contextos de ação e são, ao mesmo tempo, influenciados por esses mesmos contextos.

\section{1) A teoria Sistêmico-Funcional de Halliday}

Há várias modalidades de descrição linguística, dentre as quais se encontra a teoria sistêmica de Michael A. K. Halliday, considerado por alguns pesquisadores um funcionalismo moderado baseado na teoria de John Rupert Firth. Para esta pesquisa, teremos como base o estudo de Halliday que, segundo Neves (1997),

\footnotetext{
insiste em uma teoria não apenas extrínseca, mas também intrínseca, das funções da linguagem, uma teoria segundo a qual a multiplicidade funcional se reflete na organização interna da língua, e a investigação da estrutura linguística revela, de algum modo, as várias necessidades a que a língua serve. A pluralidade funcional se constroi claramente na estrutura linguística e forma a base de sua organização semântica e sintática, ou seja, lexical e gramatical (NEVES, 1997, p. 12).
}

De acordo com a linguística sistêmico-funcional de Halliday, a gramática, formada a partir de estruturas sistêmicas, é interpretada metafuncionalmente (NEVES, 1997, p 58-59). Desse modo, as diferentes redes sistêmicas representam diferentes tipos de significado, associando-os às diferentes funções da linguagem. Neste caso, o conhecimento da gramática nos permitiria descrever e analisar o modo como os itens lexicais são selecionados, organizados e dispostos no texto com o objetivo de produzir significado.

A teoria sistêmico-funcional propõe uma relação léxico-gramatical (estruturas gramaticais e itens lexicais) em interface com a semântica e o discurso, permitindo investigar como “a experiência é construída em termos semânticos e como essa Revista Investigações, Recife, v. 32, n. 2, p. 150 - 164, Dezembro/2019 
experiência se manifesta nos diferentes estratos da língua" (FUZER \& CABRAL, 2014, p. 25). Considerada um sistema sociossemiótico, a linguagem é um meio através do qual o homem constrói sua experiência. Desse sistema, o falante ou escritor seleciona elementos linguísticos apropriados de acordo com cada situação.

De acordo com essa teoria, a linguagem, em seu potencial de gerir e trocar significados, é utilizada pelo indivíduo no meio social para que ele possa desempenhar papeis sociais, construir experiências e estabelecer relações de modo organizado (FUZER \& CABRAL, 2014, p. 21). Segundo Halliday e Matthiessen (2004, p. 30), a linguagem constrói a experiência humana, nomeando e categorizando os elementos que fazem parte de nosso mundo para depois transformá-los em sentenças gramaticais mais complexas, o que nos leva a compreender que "não há nenhuma faceta da experiência humana que não possa ser transformada em sentido. Em outras palavras, a linguagem fornece uma teoria da experiência humana, e certos recursos da lexicogramática de cada língua são dedicados a essa função”.

Por isso, Halliday e Matthiessen (2004) propõem três metafunções da linguagem que serviriam a diferentes propósitos de comunicação: a) a função ideacional que tem por objetivo a expressão do conteúdo, ou seja, através desta função, os usuários organizam e incorporam na língua sua experiência dos fenômenos do mundo real e de sua própria consciência. Esta função pode ser subdividida em dois componentes, o experiencial e o lógico; b) a função interpessoal que corresponde ao modo como o falante usa a linguagem para participar do evento da fala: ao estabelecimento e à manutenção dos papeis sociais bem como o modo como o falante expressa o seu julgamento e estabelece suas relações com o ouvinte; e c) Textual que se refere à criação do texto. Esta função observa a organização interna e externa das frases, o seu significado como mensagem e sua relação com o contexto (NEVES, 1997, p. 12-14).

Em síntese, cada oração expressa três tipos de significado: a) os significados ideacionais, que se referem à representação linguística da realidade percebida pelo falante/escritor, assim como nos relacionamos uns com os outros; b) os significados interpessoais estão relacionados à interação entre os participantes do evento discursivo e c) os significados textuais, que se referem à organização da oração como mensagem coesa e coerente, partem de um contexto que engloba mensagens anteriores e futuras. 
De todas as três metafunções elencadas por Halliday e Matthiessen (2004), para este artigo, vamos nos deter apenas na função ideacional realizada pela função experiencial, que é responsável por um modelo de representação de mundo, e utilizaremos o sistema de transitividade, que propõe uma análise da oração em termos de processos, participantes e circunstâncias, permitindo assim construir uma experiência de mundo.

\section{2) O sistema de transitividade em análise}

Na perspectiva funcional de Halliday e Matthiessen (2004, p. 224), a transitividade é um sistema que descreve a relação entre os componentes da oração. Esses componentes (processos, participantes e eventuais circunstâncias) são considerados categorias semânticas que explicam como os fenômenos de nossa experiência de mundo são construídos na estrutura linguística:

O sistema de transitividade fornece os recursos lexicogramaticais para interpretar uma quantidade significativa de mudança no fluxo de eventos como uma figura - como uma configuração de elementos centrados em um processo. Os processos são interpretados como um conjunto gerenciável de tipos de processos. Cada tipo de processo constitui um modelo ou esquema distinto para construir um determinado domínio da experiência como uma figura de um tipo particular (HALLIDAY \& MATHIESSEN, 2004, p. 213, tradução nossa').

De acordo com Halliday e Matthiessen (2004, p. 170), esse sistema constrói, na hierarquia da oração, os significados relativos ao mundo das experiências, representando-as através de um grupo gerenciável de "tipos de processos”. Cada um desses processos tem seu próprio modelo de construção representacional que é sempre subjetivo. Para os autores, os principais tipos de processos de transitividade são o material, o mental e o relacional, mas ressaltam que há outras categorias localizadas nos limites entre eles. No limite entre os processos material e mental está o processo comportamental; no limite entre os processos mental e relacional está o processo verbal;

\footnotetext{
${ }^{1}$ The system of transitivity provides the lexicogrammatical resources for construing a quantum of change in the flow of events as a figure- as a configuration of elements centred on a process. Processes are construed into a manageable set of process types. Each process type constitutes a distinct model or schema for construing a particular domain of experience as a figure of a particular kind.
} 
e, por fim, no limite entre os processos relacional e material está o processo existencial, conforme pode ser observado na figura a seguir:

Figura 1: Tipos de processos

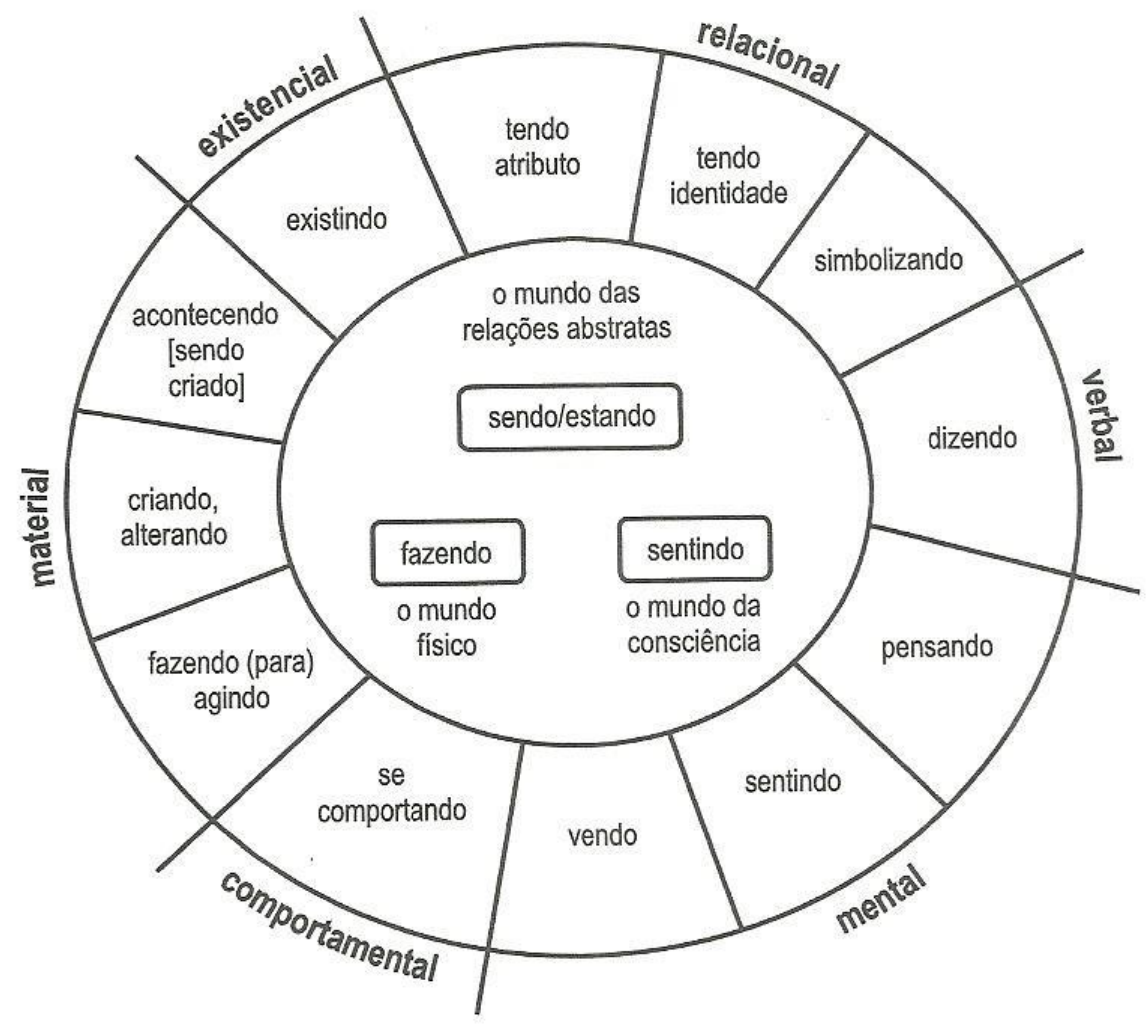

Fonte: (CUNHA \& SOUZA, 2007, p. 55)

As escolhas realizadas no sistema de transitividade dependerão das variáveis de campo (do que estamos falando), relação (quem são os participantes) e modo (qual é o canal através do qual a mensagem é construída e veiculada). A linguagem na perspectiva hallidayana é utilizada para falar dos elementos semióticos do mundo e sobre os eventos sociais que ocorrem no mundo. Cunha e Souza (2007, p. 53-54) enfatizam que "O sistema de transitividade permite identificar as ações e atividades humanas que estão sendo expressas no discurso e que realidade está sendo retratada”. Essa identificação acontece por meio de três componentes que integram o sistema: (a) o processo (verbos); (b) os participantes (substantivos e/ou grupos nominais) e (c) as circunstâncias (adjetivos e/ou advérbios). O processo é o elemento central da estrutura e os participantes estão 
diretamente envolvidos com ele, sendo que os participantes variam de acordo com o tipo de processo presente na oração:

O processo é o elemento mais central na configuração. Os participantes estão perto do centro; eles estão diretamente envolvidos no processo, provocam sua ocorrência ou são afetados de alguma forma. A natureza dos participantes irá variar de acordo com o tipo de processo e podemos dizer que a configuração do processo + participantes constitui o centro experiencial da sentença. Elementos circunstanciais aumentam esse centro de alguma forma- temporariamente, espacialmente, causalmente, e assim por diante; mas seu status na configuração é mais periférico e, ao contrário dos participantes, eles não estão diretamente envolvidos no processo (HALLIDAY \& MATTHIESSEN, 2004, p. 221, tradução nossa ${ }^{2}$.

Pelo sistema de transitividade representamos como as entidades agem, como são nomeadas e como se relacionam com o mundo. É por isso que as escolhas feitas nesse sistema revelam como o falante vê o mundo que o cerca. O que acontece quando representamos nossa experiência linguisticamente é que selecionamos tipos de processo, participantes e, ocasionalmente, circunstâncias para ordená-los em um todo significativo e essas escolhas são refletidas na estrutura sintática, lexical e semântica de nossos textos.

\section{3) A leitura crítica da reportagem "Louco por uma guerrinha”3}

A reportagem "Louco por uma guerrinha" descreve as características do governo do ex-presidente Hugo Chávez, comparando-o a um regime totalitário. Nesse discurso, Chávez é acusado de manipular eleições, perseguir a oposição e ainda cooptar o Poder Legislativo e o Judiciário a fim de se manter no poder. A revista ainda descreve, de forma detalhada, o apoio (financeiro e logístico) oferecido às FARC, bem como a suspensão das relações comerciais e diplomáticas entre Venezuela e Colômbia com o objetivo de desviar a atenção dos reais problemas internos do país venezuelano.

\footnotetext{
${ }^{2}$ The process is the most central element in the configuration. Participants are close to the centre; they are directly involved in the process, bring about its occurrence or being affected by it in some way. The nature of participants will thus vary according to the type of process and we can say that the configuration of process + participants constitutes the experiential centre of clause. Circumstantial elements augment this centre in some way-temporally, spatially, causally, and so on; but their status in the configuration is more peripheral and, unlike participants, they are not directly involved in the process.

${ }^{3}$ Os grifos dos vocábulos analisados foram feitos pela autora.
}

Revista Investigaç̃̃es, Recife, v. 32, n. 2, p. 150 - 164, Dezembro/2019 
(1) "Chávez deu armas às FARC. Agora, ele fala todo dia em uma guerra com os Estados Unidos e a Colômbia."

Em (1), a posição de ator do processo material "deu” é ocupada por Chávez e tem como recebedor "as FARC". Nesse recorte, a revista Veja destaca uma ação de Chávez que beneficia um grupo guerrilheiro na Colômbia, mas não especifica o motivo, fazendo com que o leitor deduza que o ex-presidente venezuelano esteja se preparando para uma guerra.

Em seguida, no discurso da revista, Chávez é identificado na posição de dizente do processo verbal "fala" e da verbiagem "em uma guerra com os Estados Unidos e a Colômbia”. É interessante notar que a revista Veja não assume a guerra contra os Estados Unidos e a Colômbia como uma informação sua, mas sim como o conteúdo da fala de Chávez, sugerindo que isso possa ser uma mentira ou mesmo fantasia criada pelo próprio Chávez para justificar sua ação de fornecer "armas" (meta) a um grupo guerrilheiro. A revista procura denunciar essa estratégia ao colocar, entre uma figura e outra, a circunstância de localização "agora”. Pelo uso dessa circunstância que indica tempo, a revista Veja denuncia a estratégia de Chávez de primeiro fornecer armas às FARC e, só depois, falar em guerra com os Estados Unidos e Colômbia. O uso da circunstância de localização “todo dia”, logo após o processo verbal "fala”, indica o caráter repetitivo do discurso, como se Chávez quisesse convencer a população de suas ações não pelo argumento racional, mas pela repetição.

(2) "Eleito e reeleito pelo voto popular, o tenente-coronel Hugo Chávez Frías tem torpedeado sistematicamente as instituições democráticas para implantar o que ele chama de 'Socialismo do século XXI'- uma mistura do pior que têm a oferecer o populismo, o ultranacionalismo e o esquerdismo em suas manifestações mais infantis.”

Nesse recorte, Chávez está representado como meta dos processos materiais "eleito e reeleito", que têm o mesmo ator "pelo voto popular". Esse ator, que está identificado como agente da passiva, não está especificado, ou seja, não podemos saber qual o perfil das pessoas que votaram em Chávez. Esta construção gera um efeito de consenso ao demonstrar que o ex-presidente venezuelano "foi eleito e reeleito" pela população, através do voto popular, numa clara demonstração de confiança. 
Logo em seguida, Chávez é transformado em ator do processo material transformativo "tem torpedeado". Esse processo sugere não apenas transformar a meta “instituições democráticas”, mas fazer isso por meio da violência, uma vez que o verbo "torpedear" faz parte do campo semântico de guerra e significa "atacar" e "bombardear".

O uso da circunstância de modo "sistematicamente" entre o processo "tem torpedeado" e a meta "as instituições democráticas" já demonstra que Chávez ataca, com certa regularidade, as instituições democráticas, uma ação não condizente com um governo que se diz democrático.

A justificativa para a ação de Chávez contra as instituições democráticas é exposta através de uma oração projetada que funciona como uma circunstância de causa "para implantar o que ele chama de 'Socialismo do século XXI", sugerindo que ele, não respeitando os votos recebidos, age contra a democracia apenas para concretizar um capricho.

Ao afirmar que Chávez "tem torpedeado as instituições democráticas" com a finalidade de "implantar o que ele chama de 'Socialismo do século XXI”, a revista Veja sugere também que o "Socialismo do século XXI", que se constitui em um projeto de governo de Hugo Chávez é incompatível com a democracia, uma vez que ele precise destruir as instituições democráticas de seu país para viabilizar sua implantação.

Por fim, ao definir o "Socialismo do século XXI" como "uma mistura do pior que têm a oferecer o populismo, o ultranacionalismo e o esquerdismo em suas manifestações mais infantis.", a revista aponta para um projeto nefasto que Chávez, a todo custo, tenta impor ao país.

(3) “Chávez tem apelo, em especial entre as camadas da população que nunca se sentiram representadas, e usou-muito mal, mas usou- o dinheiro do petróleo para simular melhorias para os mais desvalidos.”

Nesse recorte (3), Chávez aparece como possuidor no processo relacional atributivo possessivo "tem" e como ator no processo material "usou". No primeiro caso, ele aparece como possuidor do possuído "apelo" que, neste contexto, significa que ele tem a posse do apoio, do clamor e do pedido das massas, ou seja, ele exerce uma influência sobre a população. Essa afirmação ganha um contorno específico quando observamos o uso da circunstância de localização “entre as camadas da população que 
nunca se sentiram representadas". O discurso, assim, sugere que, devido à insatisfação ou à situação de vulnerabilidade por “nunca se sentirem representadas”, algumas pessoas seriam influenciadas pelo discurso de Chávez e, consequentemente, atenderiam a todos os seus pedidos, sugestões ou mesmo ordens.

No segundo caso, Chávez é representado como ator no processo material "usou" seguido pela meta "dinheiro do petróleo". A colocação da circunstância "muito mal" aponta para o modo como Chávez utiliza o recurso, sugerindo que ele seja incompetente para administrar não um dinheiro qualquer, mas o dinheiro proveniente do petróleo, que é considerado a maior fonte de renda do país.

Após a representação de Chávez como ator no processo material "usou”, a revista mostra o destino do recurso proveniente do petróleo "para simular melhorias para os mais desvalidos", ou seja, Chávez faz uso inadequado do dinheiro público para fingir que está investindo em melhorias para a população mais necessitada. Essa afirmação põe em evidência o caráter demagogo de Chávez e sua incompetência na administração pública, demonstrando que ele só pode usar mal o dinheiro público porque consegue exercer influência sobre as massas.

(4) “Quando Chávez não seduz pelo populismo e pelas benesses, ele usa milícias que atacam opositores-depois, finge condenar exageros, como no caso do ataque à Globovisión, baseado na premissa absurda de que gangues armadas poderiam agir em plena capital do país sem o seu beneplácito.”

Nesse excerto, Chávez é representado em duas posições que ocorrem em alternância: como experienciador no processo mental emotivo "seduz" e como ator no processo material "usa”. Essas escolhas lexicogramaticais de transitividade, usadas para construir a imagem de Chávez, apontam para alguém que ora utiliza a emoção para envolver a população, ora usa a força, através das "milícias” (meta), para conter os opositores. Em nenhum momento, Chávez é representado como um político que age de maneira equilibrada, buscando encontrar soluções de modo racional e não por meio do uso de força ou fazendo apelos emocionais. Pelo contrário, as escolhas lexicogramaticais reforçam a imagem de alguém violento e que age com agressividade, movido pelos seus instintos. 
Por fim, Chávez ocupa a posição de comportante no processo comportamental "finge" e tem como comportamento "condenar exageros, como no caso do ataque à Globovisión”. A escolha lexicogramatical de transitividade para representar o comportamento de Chávez traz uma construção discursiva condizente com aquelas construídas nos demais domínios experienciais (mental e material), representando o expresidente como uma pessoa dissimulada, imprevisível, pouco confiável e capaz de utilizar qualquer meio para se manter no poder.

(5) “Chávez dá dinheiro, guarida, armas, assistência médica e incansável apoio político às FARC, bando que controla $60 \%$ da produção e do tráfico de cocaína na Colômbia."

Em (5), Chávez é codificado com ator do processo material “dá”, que tem por meta “dinheiro, guarida, armas, assistência médica e incansável apoio político”, e recebedor “as FARC”. Ao levar um benefício ao recebedor, representado pelas FARC, Chávez aparece como inimigo da democracia, uma vez que os governos democráticos têm por princípio defender as instituições legitimamente instituídas, além de respeitarem a soberania política e jurídica de outros países.

Veja ainda define as FARC como "bando que controla $60 \%$ da produção e do tráfico de cocaína na Colômbia”, a fim de induzir o leitor à conclusão de que Chávez apoia ações de grupos criminosos em outros países, pois ele não apenas realiza a ação de dar "guarida, armas e assistência médica” como também “incansável apoio político”.

A partir dessas escolhas de transitividade, o leitor é instado a pensar "Por que Chávez quer interferir em assuntos de outros países?” ou "Por que Chávez apoia grupos criminosos contra presidentes democraticamente eleitos?", o que também remete ao fio condutor de todo o discurso da revista: de que Chávez é antidemocrático e representa uma ameaça que ultrapassa as fronteiras de seu país, expandindo-se por toda a América Latina e colocando em risco a ordem democrática de outros países.

(6) “Diante da prova irrefutável de crime, Chávez recorreu à tática habitual do contra-ataque: congelou relações diplomáticas com a Colômbia, insultou o presidente Álvaro Uribe, suspendeu o comércio bilateral e transformou o uso de bases militares colombianas por forças americanas na questão central.” 
Em (6), Chávez é posicionado como ator nos processos materiais "recorreu", “congelou”, "suspendeu”, "transformou” e como dizente no processo verbal "insultou”. Nesse recorte, a representação da experiência se encontra não apenas na escolha dos tipos de processos, mas também na disposição em que eles se encontram.

A ordem sequencial em que estão colocados os processos traz um significado específico à circunstância "Diante de prova irrefutável de crime”. Neste sentido, Chávez estaria não apenas reagindo para se eximir de uma "prova irrefutável de crime" como também para se vingar de quem denunciou. Portanto, Chávez "recorreu à tática de contra-ataque". Como? Praticando ações contra o governo colombiano: "congelou relações diplomáticas com a Colômbia” e "suspendeu o comércio bilateral”

Congelar relações diplomáticas e suspender relações comerciais são ações que costumam ser utilizadas como uma forma não militar de punir países que ameacem a paz e a segurança mundial. ${ }^{4}$

No discurso da revista Veja, a Colômbia não aparenta ser um perigo à segurança nacional, o que induz o leitor a pensar que se trata de mais uma atitude de vingança por parte do ex-presidente venezuelano por ter sido descoberto praticando um crime. A prova disso está na representação de Chávez como ator no processo material "transformou" que age sobre a meta "o uso de bases militares colombianas por forças americanas na questão central”, demonstrando que ele tentou justificar suas ações anteriores, retirando o foco do verdadeiro motivo que era esconder "a prova irrefutável de crime".

Por fim, Chávez ocupa a posição de dizente no processo verbal "insultou”, que tem como alvo o presidente colombiano Álvaro Uribe. Aqui, no Brasil, configura-se como "crime contra a honra" e está sujeito à ação penal insultar um chefe de Estado brasileiro ou estrangeiro5.

\footnotetext{
${ }^{4}$ Também chamadas de "sanções", essas ações são usadas como forma de expressar desaprovação, punir e pressionar governos com o objetivo de incentivar determinado país a mudar sua postura. Disponível em: <https://guiadoestudante.abril.com.br/blog/atualidades-vestibular/entenda-comofuncionam-as-sançoes-internacionais >. Acesso em: 08 fev. 2018.

${ }^{5} \mathrm{~A}$ ação de "insultar um Presidente da República ou o chefe de governo estrangeiro" configura-se em crime contra a honra e está previsto no código penal. Disponível em:

<https://wsaraiva.com/2013/06/12/calunia-difamaçao-e-injuria-os-crimes-contra-a-honra>. Acesso em: 08 fev. 2018.
} 
O discurso da revista Veja nos conduz ao raciocínio de que Chávez realiza uma série de ações agressivas (como insultar um outro chefe de Estado) e extremas, do ponto de vista econômico-comercial, (como suspender relações comerciais), apenas como ato de vingança e com o propósito de retirar o foco de um outro crime cometido por ele.

\section{Considerações finais}

A análise da reportagem "Louco por uma guerrinha” revelou que há um padrão lexicogramatical de representação de Chávez que aponta para a construção de uma imagem negativa que remete ao contexto ditatorial. Os recortes experienciais selecionados na análise assinalam escolhas de transitividade material, relacional, verbal, mental e comportamental que ratificam uma representação negativa de Chávez.

Há uma predominância de Chávez como ator de processos materiais, em que ele é representado como agente de ações concretas que afetam e modificam diretamente o ambiente social em que ele está inserido. No entanto, essas ações promovidas por Chávez se mostram voltadas para o universo da agressão, abusos cometidos pelo governo ou vinculadas a um propósito negativo como destruir a democracia, por exemplo. Desse modo, são atribuídas ao ex-presidente ações típicas de regimes autoritários e/ou contrárias ao conceito de democracia como atacar e se vingar de quem discorda de seu governo, perseguir a imprensa e usar um bem público, no caso o dinheiro proveniente do petróleo, para interesses particulares.

Ao enfatizar a aproximação e um possível financiamento de Chávez a grupos guerrilheiros no continente latino-americano, a revista aponta para o risco de um conflito bélico na região, ameaçando a própria estabilidade da América Latina com a possibilidade de quebra da ordem institucional em vários países.

A partir da representação negativa de Hugo Chávez, a revista Veja busca deslegitimar o seu governo, caracterizando-o como antidemocrático, centralizador e ditatorial. Assim, a revista sugere que a ameaça oferecida pela instabilidade do governo de Chávez representaria um risco para os países da América Latina, que ainda estariam lutando por solidificar suas instituições políticas e jurídicas. 


\section{Referências}

CHOULIARAKI, L.; FAIRCLOUGH, N. Discourse in late modernity. Rethinking critical discourse. Edimburgo: Edinburgh University Press, 1999.

CUNHA, M.A.F. da; SOUZA, M.M.de. Transitividade e seus contextos de uso. Rio de Janeiro, Lucerna, 2007.

FAIRCLOUGH, N. Analysing Discourse: textual analysis for social research. London: Routledge, 2003.

Discurso e mudança social. Brasília: UNB, 2001.

FUZER, C.; CABRAL, S.R.S. Introdução à gramática sistêmico-funcional em língua portuguesa. Campinas/SP: Mercado das Letras, 2014.

GIANNOTTI, V. Muralhas da linguagem. 2ª Ed. Rio de janeiro: Mauad, 2004.

HALLIDAY, M.A.K.; MATHIESEN, C. Introduction to functional grammar. $4^{\mathrm{a}}$ ed. London and New York: Routledge Taylor \& Francis Group, 2004.

MELO, I.F. Análise crítica do discurso: um estudo sobre a representação de LGBT em jornais de Pernambuco. Recife: E. Universitária da UFPE, 2010.

MENDES, F. S. Hugo Chavez em seu labirinto: o movimento bolivariano e a política na Venezuela. São Paulo: Alameda, 2012.

NEVES, M.H.M. A Gramática funcional. São Paulo: Martins Fontes, 1997.

SEVERO, L. W. Desdobramentos da entrada da Venezuela no Mercosul. Revista Orbis Latina , vol 2, No 1, janeiro-dezembro de 2012, p. 112-115. Disponível em: $<$ https://issuu.com/revistaorbislatinaorbislatina/docs/revista_orbis_latina_v2>. Acesso em: 21 ago. 2016.

* Doutora em Letras pelo departamento de Letras Clássicas e Vernáculas, da Universidade de São Paulo (USP). 